\title{
Sternoclavicular Joint Swelling in a Patient with Rheumatoid Arthritis
}

HIROYUKI NAKAMURA, MD, 3rd Department of Internal Medicine, Hokkaido P.W.F.A.C Obihiro-Kosei General Hospital; YUHEI SHIBATA, MD, 3rd Department of Internal Medicine, Hokkaido P.W.F.A.C Obihiro-Kosei General Hospital; TSUYOSHI TAKEDA, MD, PhD, 3rd Department of Internal Medicine, Hokkaido P.W.F.A.C Obihiro-Kosei General Hospital, Obihiro, Japan. Address correspondence to Dr. H. Nakamura, Hokkaido P.W.F.A.C Obihiro-Kosei General Hospital, 3rd Department of Internal Medicine, W6-S8-1, Obihiro, 080-0016, Japan. E-mail: nakahiro@med.hokudai.ac.jp. J Rheumatol 2016;43:2074-5; doi:10.3899/jrheum.160401

The sternoclavicular joint is a diarthrodial joint that can be involved in rheumatoid arthritis (RA), and is detectable by ultrasound (US) examination in $15 \%$ of patients with RA ${ }^{1}$. Methotrexate-related lymphoproliferative disorder (MTX-LPD) occurs in extranodal sites in about $40 \%-50 \%$ of the affected patients $^{2}$; however, intraarticular MTX-LPD is a very rare manifestation with only 1 case report occurring in the knee joint ${ }^{3}$.

A 67-year-old Japanese woman with a 40-year history of RA, treated with MTX (6 mg/week) for 15 years, presented to our hospital complaining of right sternoclavicular joint swelling (Figure 1A). The serum levels of C-reactive protein $(5.68 \mathrm{mg} / \mathrm{dl}$, normal <0.3), lactate dehydrogenase (325 IU/1, normal 125-237), and soluble interleukin 2 receptor (1340 $\mathrm{U} / \mathrm{ml}$, normal 145-519) were elevated. US examination of the swelling joint showed low echoic lesion accompanied with positive power Doppler. Sternoclavicular joint synovitis was suspected, and MTX was increased to $8 \mathrm{mg} /$ week, resulting in the worsening of this joint lesion (Figure 1B). Skin biopsy of the ulcerated lesion revealed CD20+ atypical lymphocytes with Epstein-Barr virus (EBV) latent membrane protein 1 and EBV-encoded RNA-1 (Figure 2). The diagnosis of MTX-LPD associated with EBV was made. The sternoclavicular joint swelling disappeared 6 months after MTX discontinuation (Figure 1C).
This sternoclavicular joint swelling is suggested to be caused by MTX-LPD in the skin overlapping a joint. Mucocutaneous ulcer associated with EBV-positive LPD can develop during immunosuppressive therapy, including MTX $^{4}$. MTX-LPD should be considered as the differential diagnosis of atypical joint swelling during the course of RA, and histopathologic examination should be carried out.

\section{REFERENCES}

1. Rodríguez-Henríquez P, Solano C, Peña A, León-Hernández S, Hernández-Díaz C, Gutiérrez M, et al. Sternoclavicular joint involvement in rheumatoid arthritis: clinical and ultrasound findings of a neglected joint. Arthritis Care Res 2013;65:1177-82.

2. Hoshida Y, Xu JX, Fujita S, Nakamichi I, Ikeda J, Tomita Y, et al. Lymphoproliferative disorders in rheumatoid arthritis: clinicopathological analysis of 76 cases in relation to methotrexate medication. J Rheumatol 2007;34:322-31.

3. Abe A, Wakaki K, Ishikawa H, Ito S, Murasawa A. A case of rheumatoid arthritis with methotrexate related lymphoproliferative diseases of the knee. Mod Rheumatol 2015 Dec 23:1-5 (E-pub ahead of print).

4. Dojcinov SD, Venkataraman G, Raffeld M, Pittaluga S, Jaffe ES. EBV positive mucocutaneous ulcer-a study of 26 cases associated with various sources of immunosuppression. Am J Surg Pathol 2010;34:405-17. 


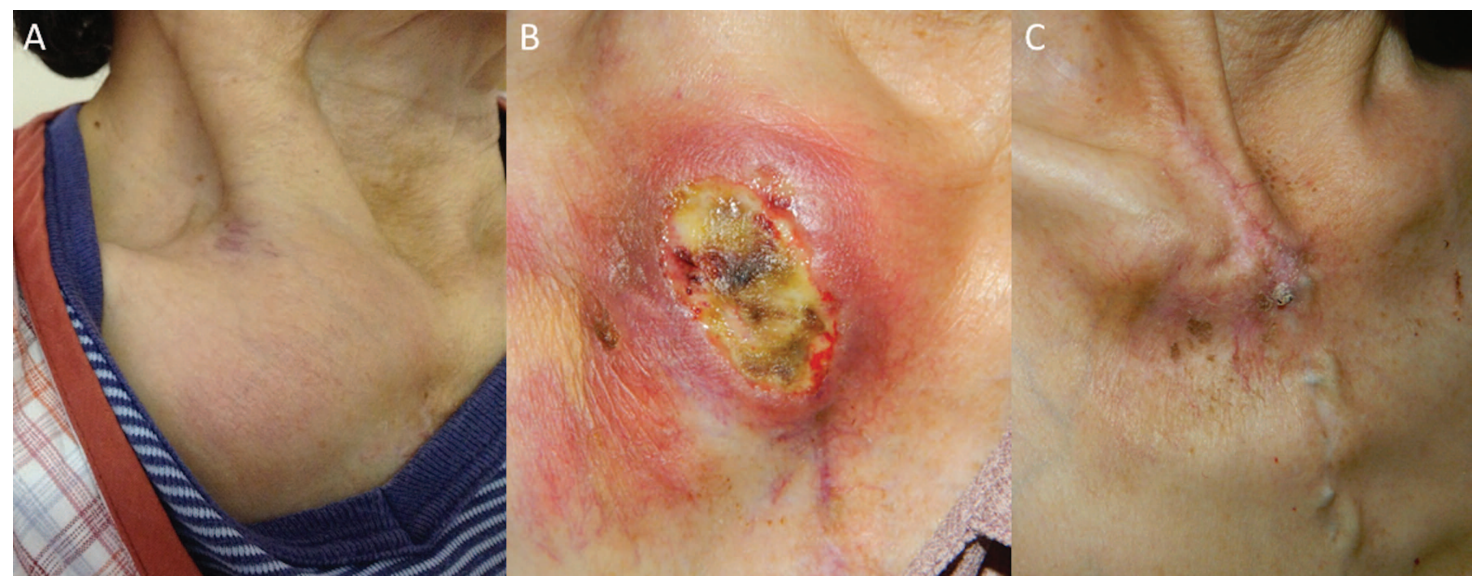

Figure 1. A. Right sternoclavicular joint swelling appeared during the course of RA treated with MTX. B. Increasing the dose of MTX caused ulceration of the sternoclavicular joint swelling. C. Discontinuation of MTX led to improvement of the lesion. RA: rheumatoid arthritis; MTX: methotrexate.

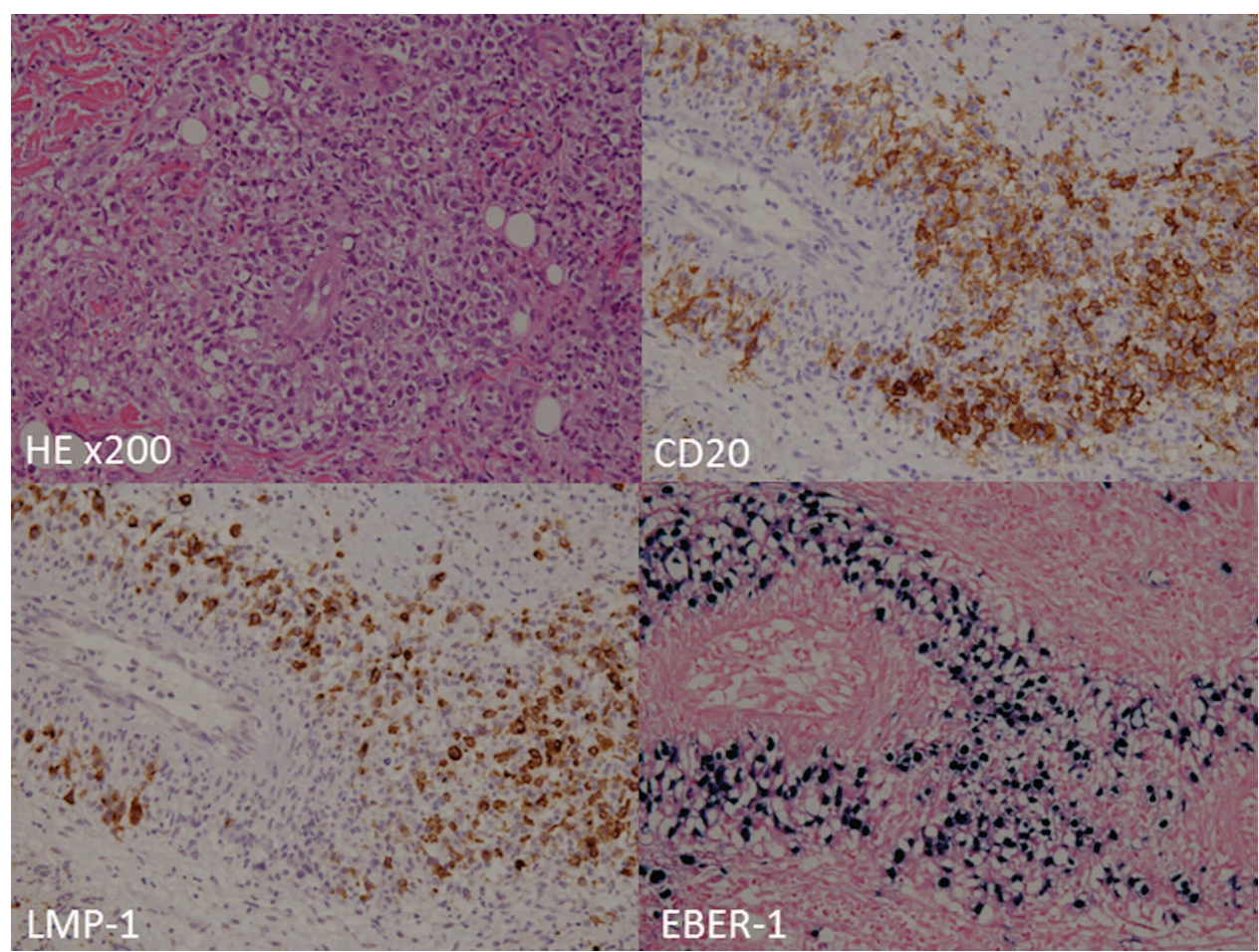

Figure 2. Skin biopsy of the sternoclavicular joint ulcer showed CD20+ atypical lymphocytes with LMP-1 and EBER-1. LMP-1: Epstein-Barr virus latent membrane protein 1; EBER-1: Epstein-Barr virus-encoded RNA-1. 